Proc. Indian Acad. Sci. (Earth Planet. Sci.), Vol. 94, No. 1, March 1985, pp. 29-34.

(C) Printed in India.

\title{
Quasi-biennial oscillation in geomagnetic disturbance field
}

\author{
G K RANGARAJAN

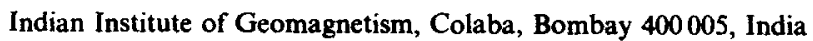

MS received 18 July 1984; revised 15 October 1984

\begin{abstract}
Using the techniques of second derivatives, digital filtering and power spectral analysis, the fine structure of the quasi-biennial oscillation $(\mathrm{QBO})$ in the equatorial geomagnetic field in the Indian zone is studied. The salient results are: (i) in the quiet day field, $Q B O$ is weak and the signal strength has no local time dependence; (ii) in the disturbance field the signal is strongest in the afternoon and evening hours and (iii) larger magnitudes are manifested closer to the dip equator. The difference in dawn and dusk amplitudes of the signal and the absence of significant strength close to noon in the electrojet region rules out EUv flux as the responsible agent.
\end{abstract}

Keywords. Quasi-biennial oscillation; geomagnetic field; second derivatives; digital filtering; power spectral analysis.

\section{Introduction}

Attempts to identify a biennial cycle in meteorological, geophysical and solar parameters through several statistical approaches have been undertaken for quite some time now. While the existence of a clear 26-month cycle has been well-established in stratospheric zonal wind oscillations and temperature, total zone, tropopause height etc (Angell and Korshover 1964) similar attempts on geomagnetic time series have met only with partial success. Stacey and Westcott (1962) found that while the QBO was noticeable at Alibag $\left(19^{\circ} \mathrm{N}\right)$ and (Apia $\left.14^{\circ} \mathrm{S}\right)$ it was very weak in Huancayo $\left(12^{\circ} \mathrm{S}\right)$, located close to the dip equator. They also suggested that while the oscillations of quietday $H$ values were periodic, it may be randomly excited. Yacob and Bhargava (1968) showed, from spectral analysis of long-series of Alibag $H$ data confined to quiet days, that the existence of 26-month variation in $\mathrm{Sq}(\mathrm{H})$ range is a reality and suggested its source as the Sun, as similar spectral peak was observed in Zurich relative sunspot number $R_{z}$. Two-year periodicity in $R_{z}$ was earlier shown to be marginally significant by Shapiro and Ward (1962). Raja Rao and Joseph (1971) utilized the technique of bandpass filter to isolate the $Q B O$ at several low latitude stations and suggested that the amplitude varied as a function of latitude. It should be reemphasized that for all these attempts quiet-time components of the geomagnetic field were utilized.

Recently Sugiura (1976) and Sugiura and Poros (1977) provided clear evidence for the existence of $\mathrm{QBO}$ in geomagnetic disturbance field and showed its close correlation with $R_{z}$ and $10.7 \mathrm{~cm}$ solar radio flux. Sugiura (1976) preferred the time domain analysis of the data because the frequency of the QBO changes with time and the spectra provide only the average characteristic. Even in time domain the signal is weakened by other natural and artificial irregular oscillations. The second order time derivatives derived from annual mean values of $\mathrm{H}$ were found to show the QBO remarkably well if the quality of the observations was very good. The annual mean eliminates the highfrequency components and the second derivative acts as an effective trend-eliminating 
filter. Sugiura and Poros (1977) mention that the second derivative of a parabola fitted to the data is equivalent to the simple three-point difference scheme for the second derivative. They also utilized the technique of digital filtering of mean monthly values of the $\mathbf{H}$ field at several stations to show clearly the existence of QBO in the disturbance field, its time variation and the correlation between stations separated in latitude and longitude, with $R_{z}$ and with $D_{x t}$.

In this paper, we proceed to analyse the geomagnetic field at Alibag (Geog. Lat. $18^{\circ}$ $38^{\prime} \mathrm{N}$, Dip $24^{\circ} \mathrm{N}$ ) and at Trivandrum (Lat. $8^{\circ} 29^{\prime} \mathrm{N}$, Dip $1^{\circ} \mathrm{S}$ ) close to the dip equator using both the techniques suggested by Sugiura. In addition, we confine the analysis to data for one hour at a time to see the nature of the local time change in the signal. Such an approach was first initiated by Bhargava (1972) in his analysis of the annual and semiannual modulation of the geomagnetic field. The motivation for this is the anticipation that if $Q B O$ is related to solar features and manifests strongly in the disturbance field then a forenoon/evening asymmetry in the strength of the signal should exist as the ring current responsible for low latitude field reduction is known to be inflated in the evening sector. Such an asymmetry was shown for the strength of the 27-day recurrence signal by Bhargava and Rangarajan (1975), and by Rangarajan and Bhattacharyya (1983).

\section{Data analysis and discussion}

\section{1 $Q B O$ in horizontal intensity through second-derivatives}

Mean monthly $H$ values at Trivandrum derived from restricting the data to only international disturbed (ID) days were combined to derive the mean annual values for each hour. This string, for each hour, was then subjected to the method of three-point difference scheme for second derivatives. According to Sugiura (1976) high frequency components are eliminated when annual means are utilized and second-order differentiation effectively eliminates variation with period in excess of 6 years. In figure 1 we show the time variation of the second derivative for some selected hours to demonstrate the variability of the signal. The main feature is the clear existence of QBO and the dependence of its strength on local time. Data for $20 \mathrm{hr}\left(75^{\circ} \mathrm{EMT}\right)$ has the most consistent signals. Sugiura and Poros (1977) caution that "the use of annual means is not recommended except for a crude survey of the presence or absence of the QBO without detailed information on the wave". We have, indeed, shown the presence of the signal.

\section{$2.2 Q B O$ in $\mathrm{H}$ at Trivandrum and Alibag through digital filters}

Here, we utilized monthly mean hourly values of $\mathbf{H}$ derived from data of international disturbed (ID) days and international quiet (IQ) days. For Alibag, the data extended for the period 1925 to 1980 , and that for Trivandrum from 1958 to 1980.

A 51-weight band pass filter was designed following Behannon and Ness (1966). The peak response was between 25 and 22.7 month as the preliminary analysis of the data indicated periodicities in this range rather than at 26 months, usually identified as the QBO. 
Results of application of this filter on long series of Alibag $\mathbf{H}$ (disturbance) data corresponding to $16 \mathrm{hr}\left(75^{\circ} \mathrm{EMT}\right)$ is shown in figure 2. This hour would have the largest signal to noise ratio for the QBO, as seen from power spectral analysis.

It becomes at once apparent that the signal strength is highly variable so that spectral analysis of such strings of data may not reveal all the facets. Close to the year of solar minimum $(1934,1944,1954,1964$. . . ) the signal nearly vanishes, the exception being that of 1975. However, several other geophysical and solar wind features were known to be different for the solar cycle 20 (1964-76) as compared to previous cycles (Gosling et al 1977). Next, we considered the filtered data for the years $1960-76$ for both the stations Trivandrum and Alibag restricting the data to IQ and ID days respectively. The data for some hours when the signals were strongest are shown in figure 3 . It is clear that

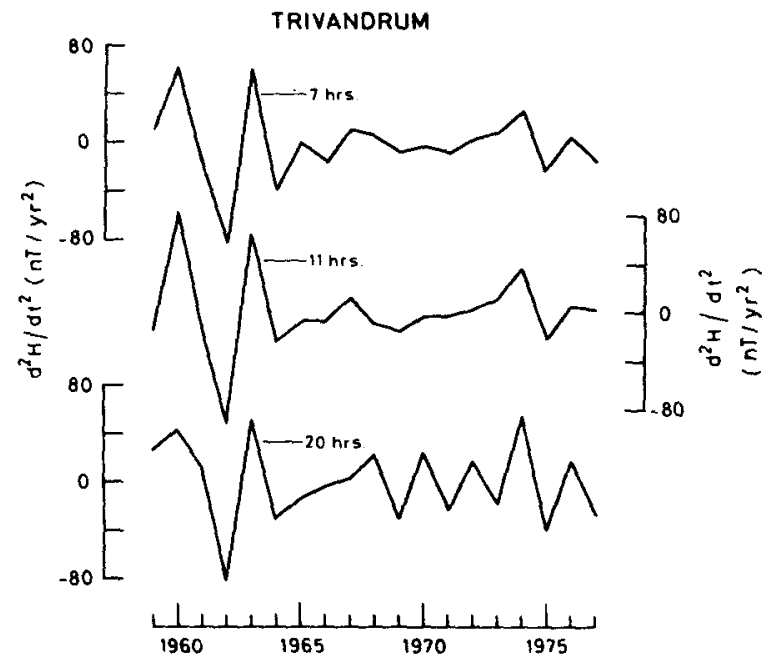

Figure 1. Time variations in second derivative of the annual mean horizontal intensity (derived from data on disturbed days only) for selected hours $\left(75^{\circ} \mathrm{EMT}\right.$ ) at Trivandrum.

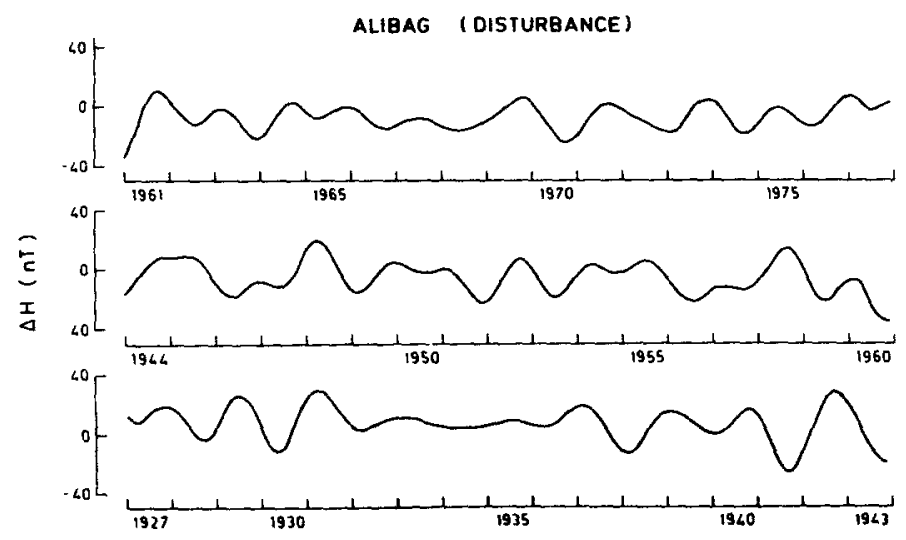

Figure 2. Band-pass filtered $H$ (disturbed days) data derived from observations at $16 \mathrm{hr}\left(75^{\circ}\right.$ EMT) at Alibag between 1927 and 1977. 
the QBO manifests more clearly in the disturbance field in relation to quiet-time fields and at Trivandrum the stationarity of the QBO seems better preserved, when compared with Alibag. The coherence of the fluctuation between the two stations is striking. For some years, as between 1960 and 1964, even the quiet day field exhibits the QBO signal.

\subsection{QBO through spectral analysis}

With the advent of fast fourier transform (FFT) routines, computation of reliable power spectra giving information on both amplitude and phase has become quite easy. Using a version of FFT (Rangarajan and Bhargava 1974) power spectra were computed for the band-pass filtered time series, restricting the data again to one hour at a time and to IQ and ID days. The local time variation in power spectral density (proportional to the square of the amplitude of $\mathrm{QmO}$ ) for Trivandrum (quiet and disturbed) and Alibag (disturbed) are shown in figure 4. From a comparison of the power densities for the two

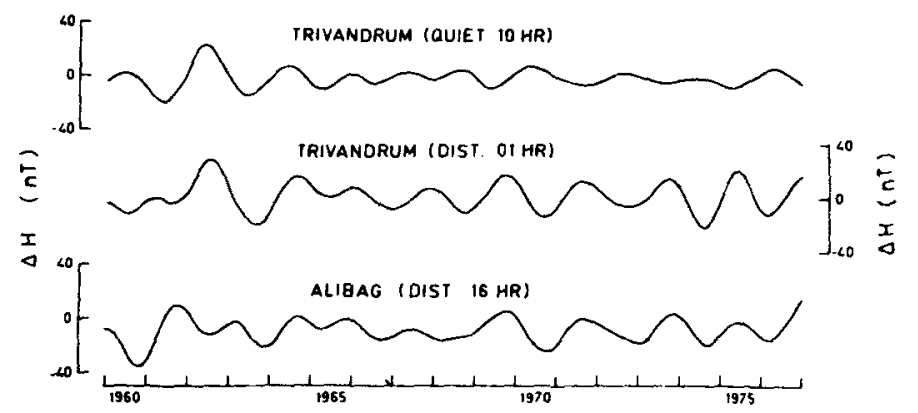

Figure 3. Band-pass filtered $H$ data from Trivandrum and Alibag between 1960 and 1976.
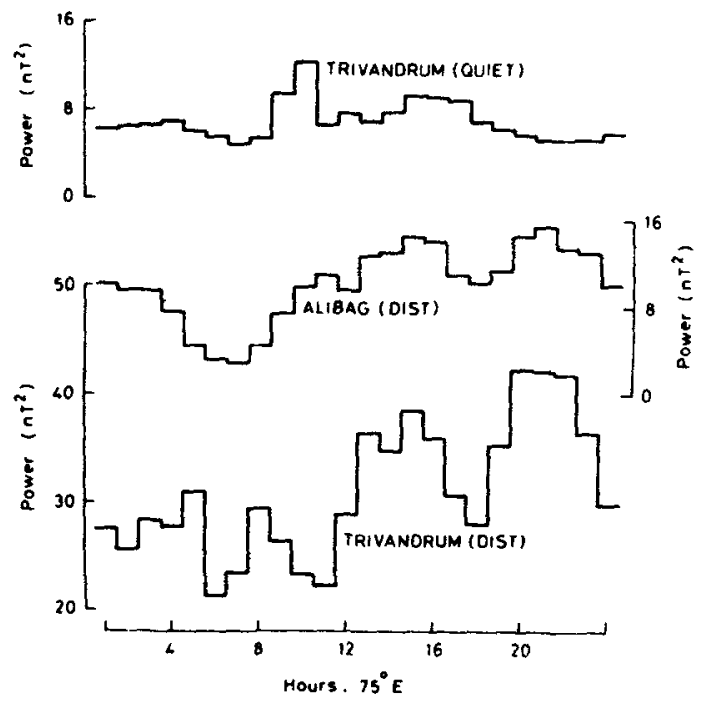

Figure 4. Local time change in the power spectral density (at quasi biennial periodicity) at Trivandrum and Alibag. 
conditions of the geomagnetic field at Trivandrum it becomes clear that during quiet times (i) power densities are smaller by a factor of 4 and (ii) there is a relatively small but significant dependence on local time. When the power densities at Alibag are compared with those of Trivandrum (disturbed field) it is seen that the QBO strength is consistently larger at Trivandrum. However the fine structure of the local time variation is quite comparable at both places with a morning minimum and two maxima in the afternoon and late evening. The afternoon maxima are consistent with the anticipation of the contribution due to asymmetric ring current, as suggested earlier in the introduction. The complex pattern of the power density variations however is not very clearly understood. Between the electrojet and non-electrojet stations, there appears a large difference (nearly a factor of 3 or 4 ) in the average level of the power spectral density. This difference may be caused by the enhanced level of continuum in the power spectra. The continuum is generally attributed to geomagnetic storm modulation of the field (Eckhardt et al 1963). Towards the dip equator, day-time disturbance field gets enhanced and consequently all periodic oscillations also have larger amplitudes and can be associated with enhanced continuum. There have been several attempts to establish the elusive link that combines solar, geomagnetic and climate changes with variable degree of success (Pittock 1978). The late-evening (20-21 hr $75^{\circ} \mathrm{E}$ time) peak suggests that for any further analysis that aims at relating solar geomagnetic and climatic changes for $\mathrm{QBO}$, the largest signals can be obtained by confining the data to this hour. The fact that there is a clear dawn/dusk asymmetry in the strength of the QBO signal and the weakness of the same close to noon clearly indicates that the responsible mechanism is not related to electromagnetic waves from the sun, consistent with Sugiura (1976) who asserts that QBO in geomagnetic field is not due to modulation of EUv flux. He suggests that the QBO in geomagnetic field, whose strength is a function of magnetic activity is due to secular variation on the sun, possibly through the interplanetary magnetic field (IMF) orientation.

\section{Conclusion}

The long series of $\mathbf{H}$ data from Alibag demonstrates the non-stationarity of the QBO signal at low latitudes. Closer to the dip equator it is seen that the QBO manifests more clearly in the disturbance field and the strength of the signal has a pronounced dusk/dawn asymmetry. This asymmetry coupled with the absence of any significant signal close to local noon even at Trivandrum suggests that EUv flux from the sun cannot be the agent responsible for the $\mathrm{QBO}$ in the geomagnetic field variations.

\section{Acknowledgement}

The author is thankful to Prof. R G Rastogi for scrutiny of the manuscript and to the referees for suggesting improvements to the paper.

\section{References}

Angell J K and Korshover J 1964 J. Atmos. Sci. 21479

Behannon K W and Ness N F 1966 NASA Tech. Note TH D-3341 
Bhargava B N 1972 Planet. Space Sci. 20423

Bhargava B N and Rangarajan G K 1975 J. Geomag. Geoelec. 27257

Eckhardt D, Larner K and Madden T 1963 J. Geophys. Res. 686279

Gosling J T, Asbridge J R and Bame S J 1977 J. Geophys. Res. 823311

Pittock A B 1978 Rev. Geophys. Space Phys. 16400

Raja Rao K S and Joseph K T 1971 J. Atmos. Terr. Phys. 33797

Rangarajan G K and Bhargava B N 1974 Proc. Indian Acad. Sci. A80 249

Rangarajan G K and Bhattacharyya A 1983 Proc. Indian Acad. Sci. (Earth Planet. Sci.) 925

Shapiro R and Ward F 1962 J. Atmos. Sci. 19506

Stacey F D and Westcott P 1962 Nature (London) 198730

Sugiura M 1976 Geophys. Res. Lett. 3643

Sugiura M and Poros D J 1977 J. Geophys. Res. 825621

Yacob A and Bhargava B N 1968 J. Atmos. Terr. Phys. 301907 